J. Lake Sci. (湖泊科学) , 2012, 24(6): 849-857

http: //www. jlakes.org. E-mail : jlakes@niglas.ac.cn

(C) 2012 by Journal of Lake Sciences

\title{
入湖河口湿地四种植物群落类型的土壤氮素空间分布特征"
}

\author{
任奎晓 ${ }^{1,2}$, 陈开宁 ${ }^{1 * *}$, 黄 蔚 ${ }^{1,2}$, 施 娴 ${ }^{1,2}$ \\ (1: 中国科学院南京地理与湖泊研究所湖泊与环境国家重点实验室,南京 210008) \\ (2: 中国科学院研究生院,北京 100049)
}

\begin{abstract}
摘 要: 对江苏省溧阳市大溪水库的洙漕河河口湿地中香蒲、水苶、灯心草和芦苇四种植物生物量、氮含量及植物群落的 土壤氮素分布特征进行研究, 结果表明: 四种植物地上生物量、地上组织氮含量、地下生物量、地下组织氮含量存在显著 差异; 土壤烧失量 $(\mathrm{LOI})$ 、总氮 $(\mathrm{TN}) 、$ 硝态氮 $\left(\mathrm{NO}_{3}^{-}-\mathrm{N}\right)$ 在垂直分布上表现为由表层向下减少的总体分布趋势, 铵态氮 $\left(\mathrm{NH}_{4}^{+}-\mathrm{N}\right)$ 浓度的剖面变化呈现先减少后增加的趋势; 四种植物群落土壤氮浓度各不同, 但均大于对照, 以有机氮为主, 说 明湿地具有一定的储氮能力; 不同的植物群落影响湿地氮素的分布. 相关性分析显示, 土壤 $\mathrm{LOI}$ 与 $\mathrm{TN} \mathrm{NO}_{3}^{-}-\mathrm{N}^{-}$和 $\mathrm{NH}_{4}^{+}-\mathrm{N}$ 均存在极显著相关性, 无机氮构成比例较小, 仅为 $1.41 \%$, 表明土壤中的氮素主要以有机氮的形式存在; 土壤氮浓度与植 物生物量及组织氮含量相关性不大, 说明土壤氮形态浓度不仅受到植物生长的影响, 同时也可能受到植物根区环境、微 生物数量与活性等的影响.
\end{abstract}

关键词: 植物群落;土壤氮;空间分布;河口湿地;大溪水库;洙漕河口

\section{Spatial distribution characteristics of soil nitrogen of four types of plant community in Zhu- cao river mouth wetland into the lake}

\author{
REN Kuixiao ${ }^{1,2}$, CHEN Kaining ${ }^{1}$, HUANG Wei ${ }^{1,2} \&$ SHI Xian ${ }^{1,2}$ \\ ( 1 : State Key Laboratory of Lake Science and Environment, Nanjing Institute of Geography and Limnology, Chinese Academy \\ of Sciences, Nanjing 210008, P. R. China) \\ (2: Graduate University of Chinese Academy of Sciences, Beijing 100049, P. R. China)
}

\begin{abstract}
Spatial distribution of nitrogen in the soil , biomass and nitrogen contents of Typha latifolia community, Polygonum hydropiper community, Juncus effuses community and Phragmites communis community in the Zhucao river mouth wetland into Daxi Reservoir in Liyang City, Jiangsu Province were studied. Significant differences of aboveground biomass, belowground biomass and nitrogen contents of four plants were found. Soil loss on ignition ( LOI), total nitrogen ( TN) and nitrate nitrogen $\left(\mathrm{NO}_{3}^{-}-\mathrm{N}\right)$ concentrations showed decreasing trend on the vertical distribution with increasing depth. Ammonium nitrogen $\left(\mathrm{NH}_{4}^{+}-\mathrm{N}\right)$ concentrations in soil profiles decreased first, and then increased. Soil nitrogen concentrations of the four plant communities were different, but most of them were higher than the control, and organic nitrogen was the main form, indicating that the wetland had a certain nitrogen storage capacity and different plant communities affected the distribution of nitrogen. The correlations between LOI and total nitrogen, ammonium nitrogen, nitrate nitrogen were significant. Inorganic nitrogen constituted only a small proportion (1.41\%), which indicated that the nitrogen mainly presented in the organic form. However, there was nearly no correlation between biomass, nitrogen contents of four types of plant and nitrogen concentrations of each soil layer. This indicated that soil nitrogen contents were affected not only by the form of plant growth, but also by the plant root zone environment, the number and activity of microorganisms.
\end{abstract} Keywords: Plant community; soil nitrogen; spatial distribution; river mouth wetland; Daxi Reservoir; Zhucao river mouth

\footnotetext{
* 国家水体污染控制与治理科技重大专项巢湖项目 (2012ZX07103-002) 和国家自然科学基金项目 (41171413) 联合 资助. 2011-12-13 收稿;2012-03-20 收修改稿. 任奎晓, 女, 1986 年生, 硕士研究生; E-mail : renkuixiao2006@ 163. com.

** 通信作者;E-mail:knchen@ niglas. ac. cn.
} 
湿地是分布于陆生生态系统和水生生态系统之间具有独特水文、土壤、植被与生物特征的生态系统, 是 自然界最富生物多样性的生态系统和人类最重要的生存环境之一. 湿地土壤是构成湿地生态系统的重要环 境因子之一, 在湿地特殊的水文和植被条件下, 湿地土壤有着独特的形成和发育过程, 具有有机质含量高和 强烈的还原环境特点 ${ }^{[1]}$. 湿地作为氮的源或汇和转换器在全球氮循环中发挥着重要作用 ${ }^{[2]}$. 氮素常是天然 湿地生态系统中最重要的限制因子之一 ${ }^{[3]}$, 也是引发江河湖泊等淡水湿地发生富营养化的重要因子. 研究 氮在湿地土壤中的分布特征, 不仅为湿地对氮的滤过作用研究 ${ }^{[4-5]}$ 和湿地管理利用提供科学依据, 而且也为 全球氮循环研究奠定基础 ${ }^{[6]}$. 由于湿地土壤是氮迁移和转化的一个重要界面, 因此, 湿地土壤氮的迁移转化 过程成为当前湿地科学和生态学研究的一个热点领域 ${ }^{[7-8]}$.

1970s 开始, Odum 等 ${ }^{[9]}$ 展开了湿地对氮素净化的研究, 随后许多学者在湿地氮素的净化方面开展了更 为广泛的研究. Wolaver 等 ${ }^{[10]}$ 的研究表明, 湿地对来自表层水的 $\mathrm{NH}_{4}^{+}-\mathrm{N} 、 \mathrm{NO}_{3}^{-}-\mathrm{N} 、 \mathrm{DON}$ 和颗粒 $\mathrm{N}$ 净吸收作用 明显. 尹澄清等 ${ }^{[5]}$ 通过对白洋淀的研究发现, 水陆交错带群落之间的小沟能有效地截留陆源营养物质, 对地 表径流 TN 的截留率可达 $42 \%$, 表明湿地对氮具有较强的截留和过滤作用.

大溪水库位于江苏溧阳市天目湖镇, 是一个以饮用水源为主的水库型湖泊. 近几年大溪水库水质下降 极为明显, 2007-2008 年的水质调查表明大溪水库总体水质属于 III类水, 而 2008-2009 年的水质调查结果 表明属于 IV 类水 ${ }^{[11]}$. 根据现场采样调查 2010-2011 年的水质有进一步下降的趋势. 洙漕河是位于大溪水库 上游 2 条主要的人湖河流之一, 河流人湖所携带的营养物质对水库水质有重要影响. 目前由于其人湖河口 湿地发育尚好, 使得库区水质下降趋势较缓, 但有关洙漕河人湖河口湿地对氮素的截留去除机制至今尚无 报道. 因此, 研究观测洙漕河河口湿地氮素分布特征, 探寻人湖河口湿地对氮素的截留去除机理, 可以为该 水库的湿地与水质管理提供重要依据. 本文通过对洙漕河河口湿地野外调查、取样分析, 研究了洙漕河河口 湿地植物、土壤氮素的分布特征及植物群落与土壤氮素含量的相关性, 以期为河口湿地生态保护和净化机 理研究提供基础数据.

\section{1 材料与方法}

\section{1 研究区概况}

大溪水库 $\left(31^{\circ} 18^{\prime} \sim 31^{\circ} 30^{\prime} \mathrm{N}, 119^{\circ} 21^{\prime} \sim 119^{\circ} 24^{\prime} \mathrm{E}\right)$ 坐落于江苏省溧阳市西南部, 属太湖流域湖西区南河 水系. 洙漕河由西南方向流人大溪水库, 河口湿地位于 $31^{\circ} 20^{\prime} \sim 31^{\circ} 23^{\prime} \mathrm{N}, 119^{\circ} 22^{\prime} \sim 119^{\circ} 23^{\prime} \mathrm{E}$. 当地气候属亚 热带季风气候, 温和湿润, 四季分明, 雨量丰沛, 平均降水量为 $1160.9 \mathrm{~mm}$.

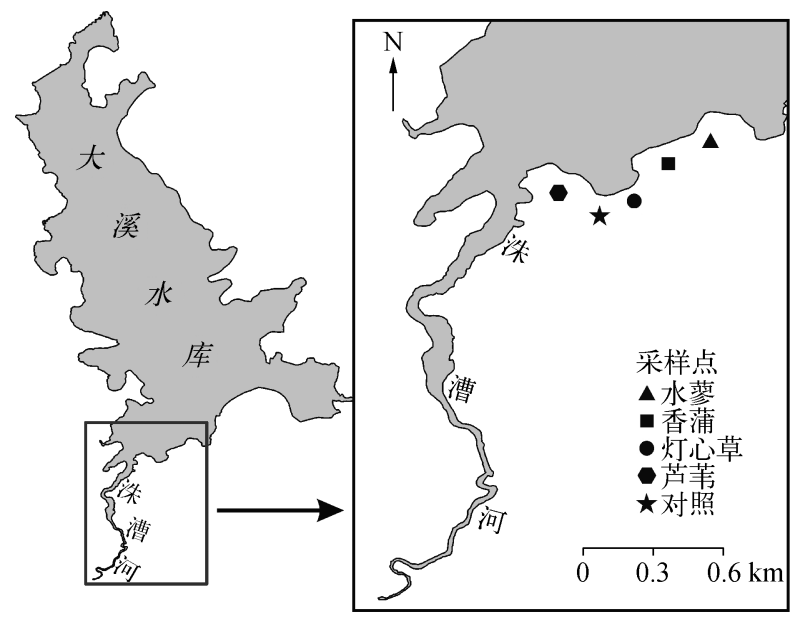

图 1 洙漕河口湿地采样点分布

Fig. 1 Distribution of sampling sites in Zhucao river mouth wetland

\section{2 样品采集}

在洙漕河河口湿地中选取香蒲 (Typha latifolia)、水蓼 (Polygonum hydropiper)、灯心 草 (Juncus effuses) 和芦苇 (Phragmites communis) 4 种优势植物群落及无植被覆盖的裸地 (对照) 作为研究对象, 以单优群落及裸地中 心作为试验区, 具体采样点分布见图 1 .

2011 年 5 月, 每种植物随机选择 $3 \sim 4$ 个样方, 样方面积为 $1 \mathrm{~m} \times 1 \mathrm{~m}$. 记录样方中 植物生长性状, 采集样方中所有植物及土壤 样品, 在无植物覆盖的裸地上采集 3 个土壤 剖面作为对照. 植物样品分为地上和地下两 部分, 去除附着土壤, 带回实验室; 土壤剖面 深度为 $10 \mathrm{~cm}$, 按 $2 \mathrm{~cm}$ 为一层共分 5 个层次 进行采集, 并对同种植物采样点的土壤样品 进行等层次混合, 土壤密封后带回实验室, 主 要测定烧失量 ( LOI) 、总氮 (TN)、硝态氮 
$\left(\mathrm{NO}_{3}^{-}-\mathrm{N}\right)$ 、铵态氮 $\left(\mathrm{NH}_{4}^{+}-\mathrm{N}\right)$. 将取回的每一份新鲜土样在实验室内快速分成 2 份,一份自然风干, 拣去石块、 贝壳等杂物, 碾磨过 100 目尼龙网, 密封保存于封口袋中用于测定土壤 LOI、TN; 另一份新鲜土样直接用来测 定 $\mathrm{NO}_{3}^{-}-\mathrm{N} 、 \mathrm{NH}_{4}^{+}-\mathrm{N}$.

\section{3 样品分析}

每个样方随机选择 $3 \sim 4$ 株植物样品放在 $80^{\circ} \mathrm{C}$ 烘箱中烘至恒重后称重, 计算得到每种植物单位面积 $\left(1 \mathrm{~m}^{2}\right)$ 生物量; 将烘干的植物样品粉碎测定植物根、茎、叶的氮质量浓度, 通过计算得到单位面积植物组织 的氮含量. 粉碎后的样品用 $\mathrm{H}_{2} \mathrm{SO}_{4}-\mathrm{H}_{2} \mathrm{O}_{2}$ 消煮制备成溶液, $\mathrm{TN}$ 用过硫酸钾氧化吸光光度法测定.

取 $105^{\circ} \mathrm{C}$ 下烘干的土壤 $3 \sim 4 \mathrm{~g}$, 在 $550^{\circ} \mathrm{C}$ 的条件下烧 $2 \mathrm{~h}$, 测定 $\mathrm{LOI}^{[12]}$; TN 测定参照《湖泊生态调查观测 与分析 $\rangle^{[13]} ; \mathrm{NO}_{3}^{-}-\mathrm{N}$ 测定参照 $《$ 土壤农化分析手册》 ${ }^{[14]} ; \mathrm{NH}_{4}^{+}-\mathrm{N}$ 的测定采用土壤溶液浸提法, 具体操作参见 Mehlich ${ }^{[15]}$ 的方法.

\section{4 统计分析}

单因素方差分析和相关分析均采用 Origin 8.5 统计软件进行.

\section{2 结果与分析}

\section{1 不同湿地植物生长状况及其生物量 分配}

调查结果显示, 湿地植物优势种香 蒲、水苶、灯心草和芦苇均生长旺盛. 4 种 湿地植物单位面积生物量在 13.5 $3100.5 \mathrm{~g}$ 之间, 其中灯心草最高, 香蒲最 低, 种间差异显著 $(P<0.05$, 表 1). 水苶 的地上/地下生物量比值最高, 达到了 18.52 , 另外 3 种的比值在 $3.13 \sim 5.03$ 之 间. 4 种植物的生物量 (干重) 及地上/地下 生物量比值存在显著差异 $(P<0.05)$.
表 1 四种湿地植物单位面积的地上、地下和总生物量 *

Tab. 1 Aboveground, belowground and total biomass per square meter of four wetland plants

\begin{tabular}{lcrc}
\hline 植物 & $\begin{array}{c}\text { 地上生物量/ } \\
\left(\mathrm{g} / \mathrm{m}^{2}\right)\end{array}$ & $\begin{array}{c}\text { 地下生物量/ } \\
\left(\mathrm{g} / \mathrm{m}^{2}\right)\end{array}$ & $\begin{array}{c}\text { 总生物量/ } \\
\left(\mathrm{g} / \mathrm{m}^{2}\right)\end{array}$ \\
\hline 香蒲 & $507.47 \pm 125.41^{\mathrm{b}}$ & $160.67 \pm 50.78^{\mathrm{b}}$ & $668.14 \pm 159.59^{\mathrm{b}}$ \\
水蓼 & $647.78 \pm 141.10^{\mathrm{b}}$ & $45.99 \pm 15.58^{\mathrm{b}}$ & $693.77 \pm 152.45^{\mathrm{b}}$ \\
灯心草 & $1524.67 \pm 563.90^{\mathrm{a}}$ & $503.67 \pm 45.26^{\mathrm{a}}$ & $2028.33 \pm 608.80^{\mathrm{a}}$ \\
芦苇 & $646.87 \pm 215.29^{\mathrm{b}}$ & $128.70 \pm 19.59^{\mathrm{b}}$ & $775.57 \pm 234.86^{\mathrm{b}}$ \\
\hline
\end{tabular}

*小写字母表示利用单因素方差分析获得的生物量显著性差异, 相同字母表示在 0.05 水平下差异不显著.

\section{2 不同植物的组织氮含量}

4 种湿地植物地上部分组织 $\mathrm{N}$ 质量浓度在 $10.99 \sim 44.41 \mathrm{mg} / \mathrm{g}$ 之间, 水苶最高, 灯心草最低, 植物间差 异显著 $(P<0.05)$; 地下部分组织 $\mathrm{N}$ 质量浓度以灯心草最高 $(12.44 \mathrm{mg} / \mathrm{g})$, 芦苇最低 $(6.49 \mathrm{mg} / \mathrm{g})$, 植物间 差异不显著 $(P>0.05)$. 除灯心草外, 其他 3 种植物的地上部分组织 $\mathrm{N}$ 质量浓度均大于地下部分. 水蓼和芦 苇地上部分又分为叶和茎, 水苶叶的浓度为 $26.81 \mathrm{mg} / \mathrm{g}$, 远高于芦苇叶浓度 $14.30 \mathrm{mg} / \mathrm{g}$; 水苶和芦苇茎的浓 度分别为 $17.60 、 9.63 \mathrm{mg} / \mathrm{g}$ (图 2a).

单位面积内 4 种湿地植物地上部分组织 $\mathrm{N}$ 含量在 $0.21 \sim 36.79 \mathrm{~g}$ 之间, 灯心草最高, 香蒲最低, 植物间 差异不显著 $(P>0.05)$; 地下部分组织 $\mathrm{N}$ 含量在 $0.04 \sim 8.97 \mathrm{~g} / \mathrm{m}^{2}$ 之间, 灯心草最高 $\left(6.40 \mathrm{~g} / \mathrm{m}^{2}\right)$, 水苶最低 $\left(0.58 \mathrm{~g} / \mathrm{m}^{2}\right)$, 植物间差异显著 $(P<0.05)$. 单位面积内 4 种植物的地上部分组织 $\mathrm{N}$ 含量均大于地下部分 (图 2b).

\section{3 湿地土壤烧失量空间分布特征}

土壤有机质的含量与有机质的输人量和输出量有关, 天然湿地土壤中的有机质主要来自动植物残骸, 有机质的输出途径则主要包括分解和侵蚀损失 ${ }^{[16]}$. 洙漕河河口湿地各植物群落土壤及裸地 (对照) 土壤烧 失量垂直分布趋势基本相似, 即总体上呈现表层向下层逐渐递减的规律, 这与植物残枝及动物残体从上到 下依次减少相一致 (图 3a). 土壤表层 $(0 \sim 2 \mathrm{~cm}$ ) 烧失量顺序为: 香蒲 $>$ 芦苇 $>$ 灯心草 $>$ 水蓼 $>$ 对照, 香蒲在 $0 \sim 2 \mathrm{~cm}$ 层烧失量最高, 达到 $5.98 \%$, 这可能与香蒲的枯枝落叶腐烂堆积及土壤微生物活性等有关. 4 种植 物群落土壤烧失量均大于对照, 但与对照的烧失量无显著性差异 $(P>0.05)$. 水平分布上, 各群落土壤及对 照土壤烧失量平均值大小顺序为: 水蓼 $(5.42 \%)>$ 芦苇 $(5.29 \%)>$ 灯心草 $(5.19 \%)>$ 香蒲 $(5.01 \%)>$ 对 照 $(4.58 \%)$, 这可能与植物生物量、植物截留有机物能力、土壤质地、微生物活性及土壤水分等有关. 在 $0 \sim$ 

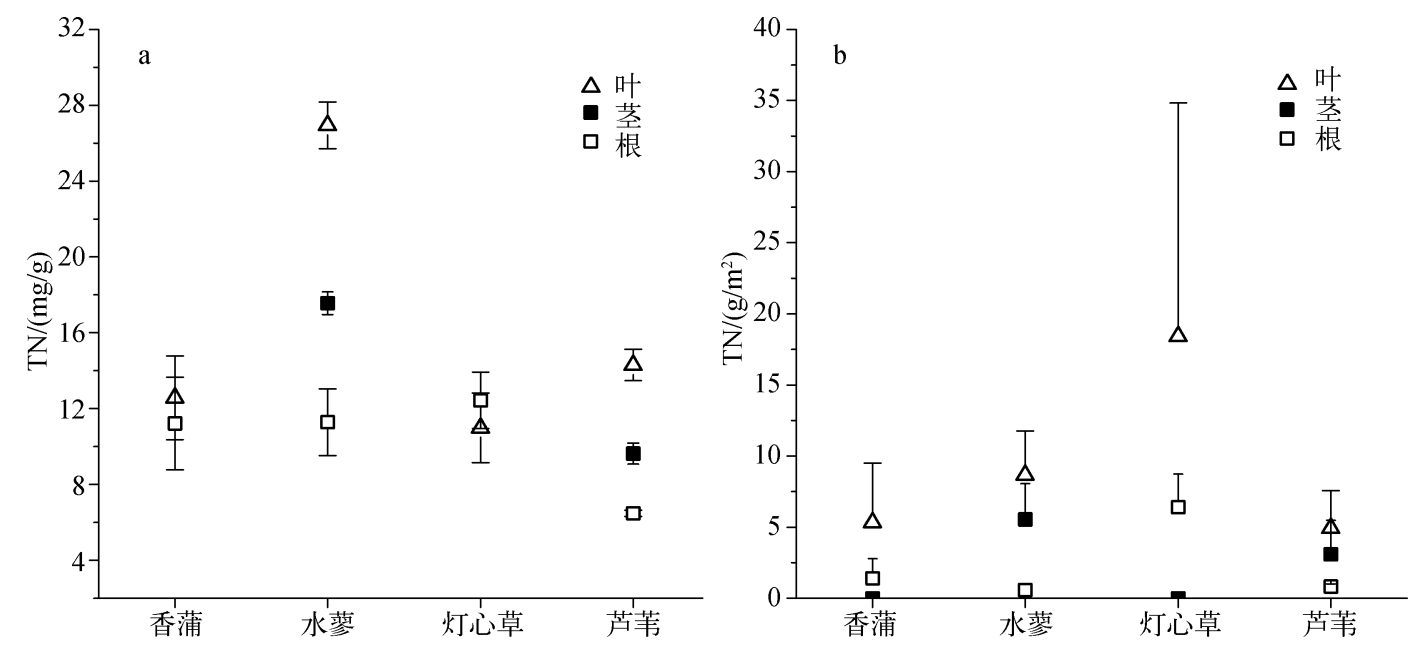

图 2 四种湿地植物地上部( 叶、茎)、地下部(根)氮质量浓度 (a) 和单位面积氮含量 (b)

Fig. 2 Nitrogen mass concentrations(a) and nitrogen contents per square meter (b) of aboveground (leaf, stem) and belowground ( root) of four wetland plants

$4 \mathrm{~cm}$ 土壤层, 香蒲 $(6.52 \%)>$ 芦苇 $(5.93 \%)>$ 灯心草 $(5.89 \%)>$ 水苶 $(5.81 \%)>$ 对照 $(5.57 \%)$, 说明香蒲 对有机污染物滞留能力大于其它 3 种植物.

\section{4 湿地土壤总氮浓度空间分布特征}

自然土壤中的氮素主要来源于生物固氮和动植物残体的分解, 也有少部分来源于大气干湿沉降. 但是 河口湿地除了上述来源外, 集水区地表径流也给湿地带来了大量的氮素. 研究发现, 湿地土壤氮的输出主要 是土壤中有机氮的分解, 分解后大部分被植物吸收利用, 部分 $\mathrm{NH}_{4}^{+}-\mathrm{N} 、 \mathrm{NH}_{3}-\mathrm{N}$ 经过硝化、反硝化作用以及氨 挥发等过程而重返大气中 ${ }^{[17]}$. 土壤总氮除了在 $2 \sim 4 \mathrm{~cm}$ 层有一个小的累积峰外 (芦苇在 $4 \sim 6 \mathrm{~cm}$ 层出现累 积峰), 其他各层的变化趋势与烧失量的变化趋势基本一致, 即垂直分布呈现递减的规律. 前 4 层 TN 含量大 小顺序均为: 水苶 $>$ 香蒲 $>$ 芦苇 $>$ 灯心草 $>$ 对照, 其中任意两种植物间均达到显著差异水平 $(P<0.05)$, 对 照与 4 种植物也达到显著差异水平 $(P<0.05)$ ( 图 3b).

\section{5 湿地土壤硝态氮浓度空间分布特征}

湿地土壤硝态氮垂直分布结果显示 (图 3c), 除芦苇在 8 10 cm 土壤层出现累积外, 其他各层的变化同总 氮的变化趋势一致. 芦苇根系具有泌氧能力, 表层以下 $10 \mathrm{~cm}$ 的土层内, 芦苇根系在 $8 \sim 10 \mathrm{~cm}$ 土壤层处分布 较多, 硝化细菌活动频繁, 所以 $\mathrm{NO}_{3}^{-}-\mathrm{N}$ 在该层较高. 水平分布上, 不同植物群落及对照土壤 $\mathrm{NO}_{3}^{-}-\mathrm{N}$ 浓度平 均值顺序为: 香蒲 $(3.09 \mathrm{mg} / \mathrm{kg})>$ 灯心草 $(2.25 \mathrm{mg} / \mathrm{kg})>$ 芦苇 $(2.03 \mathrm{mg} / \mathrm{kg})>$ 水苶 $(1.72 \mathrm{mg} / \mathrm{kg})>$ 对照 $(1.40 \mathrm{mg} / \mathrm{kg})$, 香蒲与对照之间达到显著差异水平 $(P<0.05)$.

\section{6 湿地土壤铵态氮浓度空间分布特征}

土壤垂直剖面上表层 $(0 \sim 2 \mathrm{~cm}) \mathrm{NH}_{4}^{+}-\mathrm{N}$ 含量最高, 各层土壤 $\mathrm{NH}_{4}^{+}-\mathrm{N}$ 含量呈现先减少后增加的趋势 (图 $3 \mathrm{~d})$. 上下层土壤 $\mathrm{NH}_{4}^{+}-\mathrm{N}$ 的差异与植物根系分布、微生物活动和铵态氮运移密切相关, 较深层次土壤的 $\mathrm{NH}_{4}^{+}-\mathrm{N}$ 含量大都高于较浅层次土壤, 这主要是由于较深层次土壤微生物活动较弱 ${ }^{[18]}$. 水平分布上, 各植物 群落及对照土壤 $\mathrm{NH}_{4}^{+}-\mathrm{N}$ 浓度平均值顺序: 水苶 $(34.93 \mathrm{mg} / \mathrm{kg})>$ 香蒲 $(34.07 \mathrm{mg} / \mathrm{kg})>$ 灯心草 $(31.75$ $\mathrm{mg} / \mathrm{kg})>$ 对照 $(8.71 \mathrm{mg} / \mathrm{kg})>$ 芦苇 $(5.59 \mathrm{mg} / \mathrm{kg})$, 芦苇与香蒲、水苶间分别达到显著性差异水平 $(P<$ $0.05)$. 分布在芦苇群落的土壤 $\mathrm{NH}_{4}^{+}-\mathrm{N}$ 含量在每层上均最低, 这可能与植物根系和根状茎的吸收有关, 另一 个原因是芦苇根区氧含量较高, 硝化作用较强.

\section{7 土壤氮素与烧失量及植物生物量、植物氮含量的相关性}

植物群落土壤烧失量与总氮、硝态氮及铵态氮浓度在 0.01 水平上分别显著相关 $(r=0.64 、 0.58 、 0.48)$, 
烧失量 $/ \%$

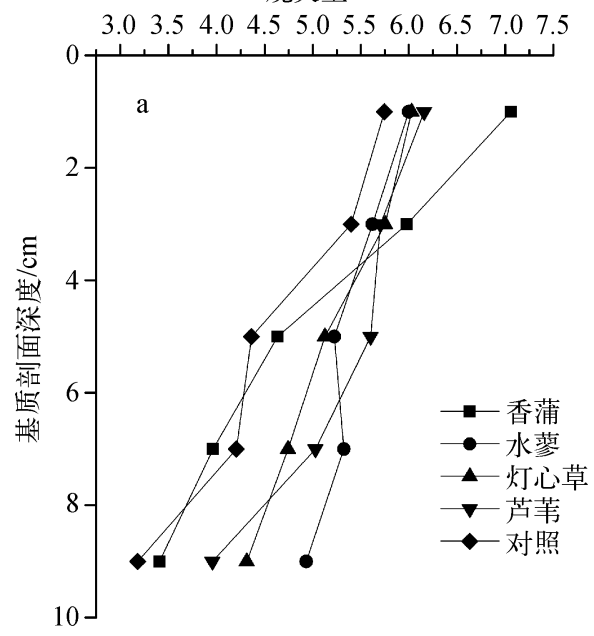

$\mathrm{NO}_{3}^{-}-\mathrm{N} /(\mathrm{mg} / \mathrm{kg})$

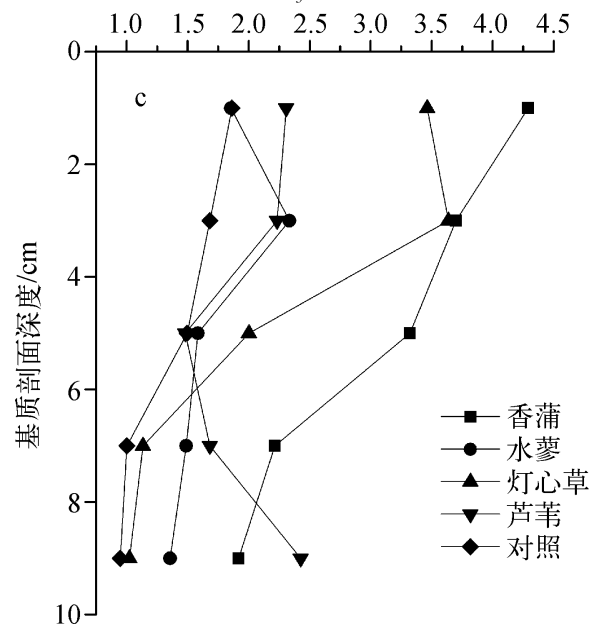

$\mathrm{TN} /(\mathrm{mg} / \mathrm{kg})$

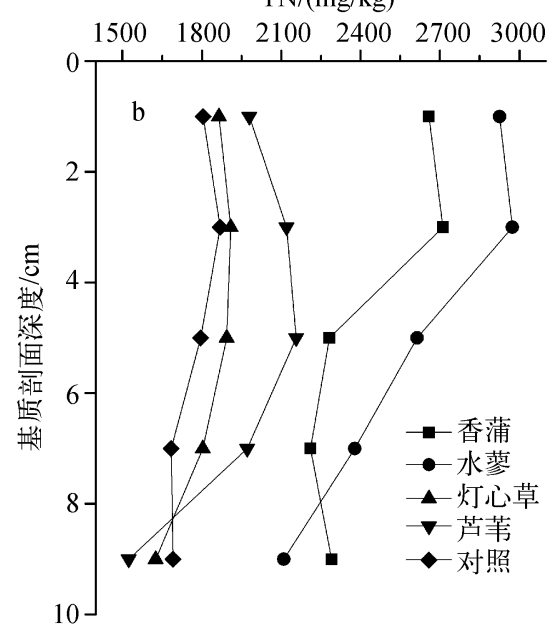

$\mathrm{NH}_{4}^{+}-\mathrm{N} /(\mathrm{mg} / \mathrm{kg})$

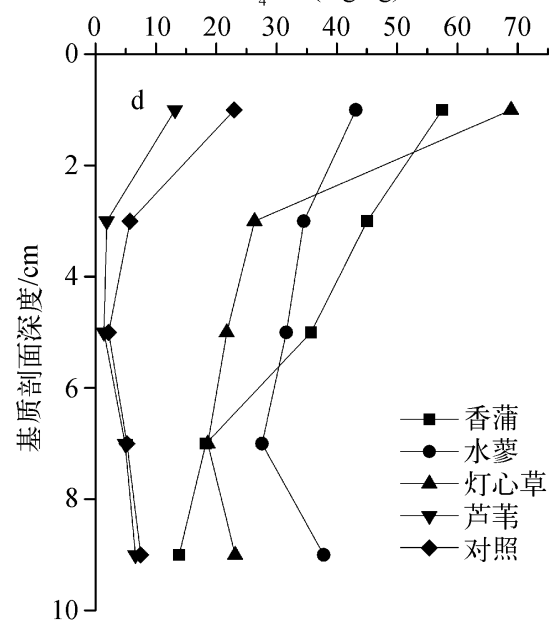

图 3 湿地土壤分层烧失量、总氮、硝态氮、铵态氮浓度

Fig. 3 Loss on ignition, total nitrogen concentrations, nitrate nitrogen concentrations and ammonium nitrogen concentrations of all soil layers

说明动植物残体分解可能是土壤氮的主要来源. 白军红等 ${ }^{[19]}$ 发现土壤中氮素含量与有机质含量显著相关, 其受淹水条件、干湿交替周期、水位以及 $\mathrm{pH}$ 值等环境因子的间接影响, 但归根结底都是通过影响土壤微生 物活动来实现的.

第 $4 \sim 6 \mathrm{~cm}$ 土壤总氮浓度与植物地下生物量、单位面积植物地下组织氮含量在 0.05 水平上显著负相关 $(r=-0.56 、-0.60)$, 与地上生物量及植物地上部分总氮含量相关性不显著, 第 $6 \sim 8 \mathrm{~cm}$ 土壤总氮浓度与单 位面积植物地下组织氮含量在 0.05 水平上显著负相关 $(r=-0.56)$, 其他各层土壤总氮浓度与植物地上、 地下生物量及其总氮浓度均无显著相关性; 第 $6 \sim 8 \mathrm{~cm}$ 土壤硝态氮浓度与单位面积植物地上组织氮含量在 0.05 水平上显著负相关 $(r=-0.57)$, 其他各层硝态氮浓度与植物的相关性均不显著, 这可能是因为硝态氮 主要与微生物种类及活性、动植物残体及根区的氧化还原环境有关; 第 $8 \sim 10 \mathrm{~cm}$ 土壤铵态氮浓度与植物地 上生物量在 0.05 水平上显著相关 $(r=0.61)$ (表 2$)$. 
表 2 土壤 $\mathrm{TN} 、 \mathrm{NO}_{3}^{-}-\mathrm{N} 、 \mathrm{NH}_{4}^{+}-\mathrm{N}$ 浓度与植物地上、地下生物量 及单位面积内总氮含量的相关系数

Tab. 2 Correlation coefficient between soil total nitrogen, nitrate nitrogen, ammonium nitrogen concentrations and plants aboveground biomass, belowground biomass and their nitrogen contents per square meter

\begin{tabular}{|c|c|c|c|c|c|}
\hline 氮形态 & $\begin{array}{c}\text { 土壤层/ } \\
\mathrm{cm}\end{array}$ & $\begin{array}{l}\text { 地上 } \\
\text { 生物量 }\end{array}$ & $\begin{array}{c}\text { 地下 } \\
\text { 生物量 }\end{array}$ & $\begin{array}{c}\text { 地上组织 } \\
\mathrm{N} \text { 含量 }\end{array}$ & $\begin{array}{c}\text { 地下组织 } \\
\mathrm{N} \text { 含量 }\end{array}$ \\
\hline \multirow[t]{5}{*}{$\mathrm{TN}$} & $0 \sim 2$ & 0.51 & -0.33 & 0.37 & -0.36 \\
\hline & $2 \sim 4$ & 0.33 & -0.46 & 0.06 & -0.46 \\
\hline & $4 \sim 6$ & 0.22 & $-0.56^{*}$ & -0.26 & $-0.60^{*}$ \\
\hline & $6 \sim 8$ & 0.23 & -0.44 & -0.40 & $-0.56 *$ \\
\hline & $8 \sim 10$ & -0.05 & -0.39 & -0.34 & -0.43 \\
\hline \multirow[t]{5}{*}{$\mathrm{NO}_{3}^{-}-\mathrm{N}$} & $0 \sim 2$ & -0.22 & 0.03 & -0.08 & 0.31 \\
\hline & $2 \sim 4$ & -0.13 & 0.19 & 0.37 & 0.43 \\
\hline & $4 \sim 6$ & -0.24 & 0.01 & -0.40 & -0.02 \\
\hline & $6 \sim 8$ & -0.24 & -0.39 & $-0.57^{*}$ & -0.48 \\
\hline & $8 \sim 10$ & -0.15 & -0.27 & -0.37 & -0.24 \\
\hline \multirow[t]{5}{*}{$\mathrm{NH}_{4}^{+}-\mathrm{N}$} & $0 \sim 2$ & -0.17 & 0.17 & 0.07 & 0.34 \\
\hline & $2 \sim 4$ & -0.11 & -0.35 & 0.03 & -0.10 \\
\hline & $4 \sim 6$ & -0.01 & -0.48 & 0.14 & -0.12 \\
\hline & $6 \sim 8$ & 0.34 & -0.35 & 0.06 & -0.12 \\
\hline & $8 \sim 10$ & 0.61 * & -0.16 & 0.30 & 0.08 \\
\hline
\end{tabular}

* 表示显著性差异, $P<0.05$ (双尾检验).

\section{3 讨论}

\section{1 湿地对氮的滞留作用}

湿地具有较高的储 $\mathrm{N}$ 能力, 挺水植物 每天每平方米累积氮达到 $20 \sim 100 \mathrm{mg}$, 相 当于输人的溶解态无机氮的 $66 \%$ $100 \%{ }^{[20]}$. 湿地植被特别是植物根的泌氧 作用、根的分泌物和表皮脱落物能够改善 微生物生长的环境, 促进根际、根区微生 物的生长 ${ }^{[8]}$, 而微生物的活动又能够影 响沉积物内部氮素的相互转化, 使得长 有植物地段的湿地沉积物滞留氮素的能 力保持较高的水平. 本研究中, 植物群落 土壤表层沉积物中 $\mathrm{TN}$ 浓度平均为 $2357.39 \mathrm{mg} / \mathrm{kg}$, 对照只有 $1804.92 \mathrm{mg} / \mathrm{kg}$, 说明植物群落地段均有一定的滞留氮 能力.

除沉积作用和植物吸收外, 植被生长 特征也影响着湿地土壤中氮的含量分布. 本研究中 4 种植物各组织 $\mathrm{N}$ 质量浓度, 除 了灯心草外,都是地上部分 > 地下部分, 在根、茎和叶分化显著的 2 种植物中 ( 水 苶和芦苇), 都呈现出叶 > 茎 > 根的组织 $\mathrm{N}$ 质量浓度, 这与蒋跃平等 ${ }^{[21]}$ 的研究结

果相似. 蒋跃平等 ${ }^{[21]}$ 的研究表明, 植物体的 $\mathrm{N}$ 积累量主要集中在植物的地上部分, 所以通过对植物地上部 分的收割, 就可以有效去除湿地中的 $\mathrm{N}$ 含量. 从植物收割结果来看, 长有植物的湿地中 $4 \% \sim 11 \%$ 的氮是由 植物收割去除的, $89 \% \sim 96 \%$ 是由反硝化作用去除的 ${ }^{[22]}$.

本研究中植物地上生物量与土壤 $8 \sim 10 \mathrm{~cm}$ 铵态氮浓度、植物地下生物量与土壤 $4 \sim 6 \mathrm{~cm}$ 总氮浓度、单 位面积植物地下部分总氮含量与 $4 \sim 8 \mathrm{~cm}$ 总氮浓度分别具有显著相关性. 植物地上生物量与土壤总氮的相 关性小, 与高英志等 ${ }^{[23]}$ 的研究结论一致, 说明土壤总氮可能不是植物绿色生物量形成的有效性氮素指标; 高 英志等 ${ }^{[23]}$ 的研究说明植被绿色生物量与土壤硝态氮浓度呈显著负相关关系, 而本研究中植物地上部分生物 量及总氮含量与土壤硝态氮浓度分别存在负相关性, 但是相关关系不显著, 这可能与研究地点周围环境差 异有关; 土壤某些层次铵态氮浓度与植物生物量存在显著相关性, 说明土壤铵态氮可能对植物的生长具有 重要的贡献. 这种贡献通过植物对铵态氮的直接吸收以及微生物调控土壤铵态氮的转化来实现. 以上相关 性分析说明植物生长初期从土壤中获取的氮养分仅仅是土壤氮素含量的少部分, 即植物吸收在湿地对氮的 滞留与去除中所占比例较小. 武维华 ${ }^{[24]}$ 的研究显示, 湿地植物的吸收作用只占植物体中 $\mathrm{N}$ 素的 $0.3 \% \sim$ $1.0 \%$.

有研究证明湿地去除污染物 (如垃圾场渗滤液) 的能力较大, 且能够维持较长时间 ${ }^{[25]}$, 但这种去除并不 是永久的, 因为湿地能力有限只能临时储存输人的污染物 ${ }^{[26]}$. Croffman 等 ${ }^{[27]}$ 认为, 河边地带的植物在夏季 吸收了氮的大部分滞留量; 而在冬季休眠期脱氮作用是主要过程, 反硝化、氨挥发和有机氮的持留是氮去除 的主要方式,硝态氮从土壤表层向下层淋溶限制了反硝化作用去除氮的过程 ${ }^{[28]}$.

\section{2 不同植物群落对土壤氮形态分布的影响}

在气候条件、土壤成土母质、水文和地貌特征相似的情况下, 土壤中氮素含量受到植被类型、植被覆盖度 以及植物残体输人量的影响 ${ }^{[29]}$. 本研究中同种植物群落土壤总氮浓度从表层到底层总体上呈现逐渐减小的趋 
势, 任意两种植物群落之间分别达到显著差异水平. 水苶群落土壤总氮浓度最高, 达 $2600.43 \mathrm{mg} / \mathrm{kg}$, 灯心草群 落土壤总氮浓度最低, 仅 $1819.60 \mathrm{mg} / \mathrm{kg}$. 灯心草群落土壤总氮浓度较低, 这可能与该群落上一年归还土壤 的氮素较其他植物群落少有关. 另外, 根系分布的深浅也影响着土壤总氮的含量. Downin 等 ${ }^{[3,30]}$ 发现温带生 态系统中的河流湿地在尚未受到严重干扰的情况下常富含可溶性有机氮 (DON), 约为总氮的 $35 \%$. 土壤中 的矿质态 $\mathrm{N}$ 是湿地生态系统中总 $\mathrm{N}$ 库的过渡库, 主要包括 $\mathrm{NH}_{4}^{+}-\mathrm{N}$ 和 $\mathrm{NO}_{3}^{-}-\mathrm{N}$, 该形态 $\mathrm{N}$ 素可被植物直接吸 收和利用, 但其浓度较低. 本研究中土壤总氮主要以有机氮的形态存在, 所占比例均在 $94 \%$ 以上, 而无机氮 构成比例较小. $\mathrm{NH}_{4}^{+}-\mathrm{N}$ 和 $\mathrm{NO}_{3}^{-}-\mathrm{N}$ 两种形态仅占到了 $0.07 \% \sim 5.53 \%$, 平均为 $1.41 \%$, 而且不同植物群落类 型土壤无机氮比例也是不同的, 结果表明: 香蒲群落土壤硝态氮占总氮的比例最高, 达到 $0.13 \%$, 灯心草为 $0.12 \%$, 芦苇为 $0.11 \%$, 水苶最低为 $0.07 \%$; 灯心草群落土壤表层 $(0 \sim 2 \mathrm{~cm})$ 铵态氮比例高达 $3.70 \%$, 整个 剖面均值为 $1.74 \%$, 其次为香蒲和水苶 $1.36 \%$, 芦苇群落的铵态氮比例仅 $0.30 \%$. 水苶和香蒲群落土壤无 机氮浓度最高, 芦苇群落无机氮浓度最低, 4 种植物群落土壤无机氮均以铵态氮为主. 土壤中硝态氮和铵态 氮的浓度主要来源于土壤有机氮的氨化和硝化等由土壤微生物进行的矿化作用, 因此其浓度的高低受土壤 有机质含量、微生物类型和土壤环境条件,如土壤温度、湿度和盐碱度等的多重影响 ${ }^{[31]}$.

不同植物群落之间硝态氮浓度无显著性差异, 其原因可能包括如下几种: 调查期间, 大溪水库处于低水 位运行状态, 河口湿地某些地段干旱而出现地面龟裂的现象; 植物生长初期不易使硝态氮的累积量表现出 不同; 植物根部的微生物数量、活性等不同, 不同植物残体分解程度不同; $\mathrm{NO}_{3}^{-}-\mathrm{N}$ 具有高的流动性, 同 $\mathrm{NH}_{4}^{+}-\mathrm{N}$ 相比更容易通过扩散和质流进人根内 ${ }^{[32]}$, 节省了植物能量的消耗, 所以 $\mathrm{NO}_{3}^{-}-\mathrm{N}$ 更容易被植物吸收利用. 导 致 $\mathrm{NO}_{3}^{-}-\mathrm{N}$ 浓度差异的直接原因是反硝化作用, 表层与下层土壤中 $\mathrm{NO}_{3}^{-}-\mathrm{N}$ 浓度差异是由溶解氧含量不同造 成的 ${ }^{[33]}$, 因为表层土壤的好氧环境不适合厌氧菌的生长使得反硝化率较低, 所以硝态氮在垂直分布上总体 呈现逐渐降低的趋势.

同种植物群落下土壤的铵态氮浓度在垂直分布上由上层到下层呈现先减少后增加的趋势, 这主要与植 物根系分布、微生物活动和铵态氮运移密切相关 ${ }^{[18]}$. 不同植物群落下土壤铵态氮浓度存在显著差异, 其中水 苶群落、香蒲群落和灯心草群落的土壤铵态氮浓度远高于芦苇群落. 由于铵态氮主要来源于氨化细菌对有 机氮的分解, 所以水苶、香蒲和灯心草群落土壤高铵态氮浓度表明这些植物群落所处的环境条件更有利于 氨化细菌对有机氮的矿化分解 ${ }^{[34]}$. 芦苇群落土壤剖面 $8 \sim 10 \mathrm{~cm}$ 的铵态氮浓度仅次于土壤表层 $(0 \sim 2 \mathrm{~cm})$, 占总氮比例达到 $0.43 \%$, 与白军红等 ${ }^{[19]}$ 的研究结论一致的是芦苇群落较深层的铵态氮浓度稍高于较浅层 的浓度, 这可能是因为深层次土壤微生物活性较弱. Kemp 等 ${ }^{[35]}$ 研究表明, 由于植物的存在而形成的根区微 生态环境对于底泥中发生的硝化和反硝化作用非常重要, 因为微生物的生长离不开各种营养物质, 根系的 分泌物为微生物的生长提供碳源. 植物根系的呼吸作用导致氧气的消耗, 从而形成厌氧微环境, 促进反硝化 的进行 ${ }^{[36]}$. 同时, 湿地植物将氧气从上部输送到根部, 在根区或根际形成一种好氧环境, 促进有机物质的分 解和硝化细菌的生长, 从而达到去除氮和其他污染物的目的 ${ }^{[37]}$.

\section{3 土壤有机质对土壤氮素浓度的影响}

有机质及氮素输人和输出量的相对大小决定了土壤中有机质和氮素的含量 ${ }^{[38]}$. 本研究中水蓼群落土壤 有机质含量及总氮浓度最高, 且水蓼单株生物量及组织氮质量浓度也是 4 种植物中最高的. 通过现场调查 发现, 往年的水苶调落物已大部分归还到土壤中, 少部分水苶残体仍存在, 这说明枯落物的高输人率可能导 致了水苶群落土壤有机质和氮素含量高. 氮素的垂直分布特征与土壤有机质的分布规律相似, 表层土壤有 机质含量丰富, 其氮素含量高, 剖面下层土壤有机质含量较低, 对应地, 其氮素含量也较少 ${ }^{[39]}$, 本研究与上述 结论稍有不同, 表层 $(0 \sim 2 \mathrm{~cm})$ 土壤烧失量最高, 而总氮在第 $2 \sim 4 \mathrm{~cm}$ 或 $4 \sim 6 \mathrm{~cm}$ 土壤层含量最高. 研究发 现, 土壤有机质与总氮、硝态氮及铵态氮之间分别具有显著的相关性, 与白军红等 ${ }^{[19]}$ 的研究结果一致, 表明 土壤氮素主要以有机氮的形式存在于土壤有机质中. 植物生长季节大量吸收土壤的氮养分, 促进了有机氮 向无机氮的转化, 因此, 湿地植被对氮素的滞留与去除具有重要的作用.

\section{4 结论}

1) 洙漕河河口湿地 4 种植物群落的生物量存在很大的差异性, 在 5 月份灯心草最高, 香蒲最低; 各组织 
$\mathrm{N}$ 质量浓度差异显著, 水苶最高, 灯心草最低, 除灯心草外, 其他 3 种植物均是地上组织质量浓度 $>$ 地下组织 氮质量浓度,而单位面积内植物组织氮含量均是地上部分 > 地下部分.

2) 土壤 LOI 在垂直分布上由上层到下层总体上呈现逐渐递减的规律, 水平分布大小顺序为: 水蓼 > 芦 苇 $>$ 灯心草 $>$ 香蒲 $>$ 对照; 总氮在垂直分布上除了在 $2 \sim 4 \mathrm{~cm}$ 层有一个小的累积峰外 (芦苇在 $4 \sim 6 \mathrm{~cm}$ 出现 累积峰), 变化趋势同 LOI, 水平分布上大小顺序为: 水蓼 $>$ 香蒲 $>$ 芦苇 $>$ 灯心草 $>$ 对照; 硝态氮在垂直分布 上同总氮的变化趋势一致 (除芦苇在 $8 \sim 10 \mathrm{~cm}$ 层出现累积外), 水平分布大小顺序为: 香蒲 $>$ 灯心草 $>$ 芦苇 $>$ 水苶 $>$ 对照; 铵态氮在垂直分布上呈现先减少后增加的变化趋势, 水平分布大小顺序为: 水苶 $>$ 香蒲 $>$ 灯 心草 $>$ 对照 > 芦苇. 表明湿地中各植物群落对氮素均具有一定滞留与去除能力.

3) 土壤有机质与总氮、硝态氮及铵态氮之间具有显著相关性, 土壤氮素主要以有机氮的形式存在于土 壤有机质中.

\section{5 参考文献}

[ 1 ] 雷 婷. 鄱阳湖南矶山湿地土壤对氮的吸附与释放特性初步研究 [ 学位论文].南昌: 南昌大学,2008.

[2] 白军红,邓伟,朱颜明等. 湿地土壤有机质和全氮含量分布特征对比研究一以向海与科尔沁自然保护区为例. 地理科学, $2002,22(2): 232-237$.

[ 3 ] Mitsch WJ, Gosselin JG. Wetlands: 3rd ed. New York: Van Nostrand Reinhold Company Inc, 2000: 89-125.

[ 4 ] 曲向荣, 贾宏宇, 张海荣等. 辽东湾芦苇湿地对陆源营养物质净化作用的初步研究. 应用生态学报, 2000, 11 (2): 270-272.

[ 5 ] 尹澄清. 内陆水一陆地交错带的生态功能及其保护与开发前景. 生态学报, 1995,15(3):331-335.

[ 6 ] 白军红,邓 伟,张玉霞. 莫莫格湿地土壤氮磷空间分布规律研究. 水土保持学报,2001,15(4):79-81.

[ 7 ] 孙志高, 刘景双, 于君宝等. ${ }^{15} \mathrm{~N}$ 示踪技术在湿地氮素生物地球化学过程研究中的应用进展. 地理科学, 2005,25 (6):6762-6768.

[8] 白军红,邓 伟,王庆改. 湿地氮素传输过程研究进展. 生态学报, 2005,25(2):326-333.

[ 9 ] Odum HT, Ewel KC, Mitsch WJ et al. Recycling treated sewage through cypress wetlands in Florida. In: D’Itri FM ed. Wastewater renovation and reuse. New York: Marcel Dekker Press, 1977: 35-67.

[10] Wolaver TG, Zieman JC, Wetzel R et al. Tidal exchange of nitrogen and phosphorus between a mesohaline vegetated marsh and the surrounding estuary in the lower Chesapeake Bay. Estuarine, Coastal and Shelf Science, 1983, 16 (3): 321-332.

[11] 王晓杰,贾锁宝. 氮类指标对湖库水质评价结果的影响分析. 江苏水利, 2009, (5):35-38.

[12] Hakanson L, Jansson M. Principles of lake sedimentology. New York: Springer-Verlag, 1983.

[13] 黄祥飞. 湖泊生态调查观测与分析. 北京:中国标准出版社,1999.

[14] 鲍士旦.土壤农化分析:第 3 版. 北京:中国农业出版社,2000.

[15] Mehlich A. Determination of $\mathrm{P}, \mathrm{Ca}, \mathrm{Mg}, \mathrm{K}, \mathrm{Na}$, and $\mathrm{NH}_{4}$. Raleigh: Soil Testing Division Pub. North Carolina Dep. of Agriculture, 1953: 1-53.

[16] 白军红,邓 伟,张玉霞等. 洪泛区天然湿地土壤有机质及氮素空间分布特征. 环境科学, 2002,23(2): 77-81.

[17] Huilin X. Climate change in relation to soil organic matter. Soil and Environmental Sciences, 1999, 8 (4) : 300-304.

[18] 白军红, 崔保山, 李晓文等. 向海芦苇沼泽湿地土壤铵态氮含量的季节动态变化. 草业学报, 2006,15(1) : 117-119.

[19] 白军红, 邓伟, 朱颜明等. 水陆交错带土壤氮素空间分异规律研究——月亮泡水陆交错带为例. 环境科学学 报,2002,22(3):343-348.

[20] Romero JA, Comín FA, García C. Restored wetlands as filters to remove nitrogen. Chemosphere, 1999, 39(2) : 323-332.

[21] 蒋跃平, 葛 滢, 岳春雷等. 轻度富营养化水人工湿地处理系统中植物的特性. 浙江大学学报: 理学版, 2005, 32 (3) : 309-313.

[22] Lin YF, Jing SR, Wang TW et al. Effects of macrophytes and external carbon sources on nitrate removal from groundwater in constructed wetlands. Environmental Pollution, 2002, 119(3): 413-420.

[23] 高英志, 汪诗平, 韩兴国等. 退化草地恢复过程中土壤氮素状况以及植被地上绿色生物量形成关系的研究. 植物生 态学报,2004,28(3):285-293.

[24] 武维华. 植物生理学. 北京: 科学出版社, 2003 . 
[25] Fernandes L, Warith MA, La Forge F. Modelling of contaminant transport within a marshland environment. Waste Management, 1996, 16(7): 649-661.

[26] Helfield JM, Diamond ML. Use of constructed wetlands for urban stream restoration: a critical analysis. Environmental Management, 1997, 21(3): 329-341.

[27] Groffman PM, Gold AJ, Simmons RC. Nitrate dynamics in riparian forests: microbial studies. Journal of Environmental Quality, 1992, $21(4)$ : 666-671.

[28] Martin JF, Reddy KR. Interaction and spatial distribution of wetland nitrogen processes. Ecological Modelling, 1997,105 (1) : 1-21.

[29] 朱清海, 毛 艳, 朱浩峥等. 辽宁省盘锦地区滨海盐渍土在发展生态农业条件下土壤肥力的变化. 生态学杂志, $1996,15(5): 36-40$.

[30] 白军红, 李晓文, 崔保山等. 湿地土壤氮素研究概述. 土壤, 2006,38(2):143-147.

[31] Chen J, Stark JM. Plant species effects and carbon and nitrogen cycling in a sagebrush-crested wheatgrass soil. Soil Biology and Biochemistry, 2000, 32(1) : 47-57.

[32] Barber SA. Soil nutrient bioavailability : a mechanistic approach. New York: John Wiley \& Sons Inc, 1995.

[33] 黄瑞农. 环境土壤学. 北京: 高等教育出版社,1994:145-146.

[34] Nikolausz M, Kappelmeyer U. Diurnal redox fluctuation and microbial activity in the rhizosphere of wetland plants. European Journal of Soil Biology, 2008, 44(3) : 324-333.

[35] Kemp WM, Sampou P, Caffrey J et al. Ammonium recycling versus denitrification in Chesapeake Bay sediments. Limnology and Oceanography, 1990, 35(7): 1545-1563.

[36] 阮晓红, 张 瑛, 黄林楠等. 微生物在湿地氮循环系统的效应分析. 水资源保护,2004,20(6):1-7.

[37] 梁 威, 胡洪营. 人工湿地净化污水过程中的生物作用. 中国给水排水,2003,19(10):28-31.

[38] Trumbore SE, Chadwick OA, Amundson R. Rapid exchange between soil carbon and atmospheric carbon dioxide driven by temperature change. Science, 1996, 272(5260) : 393-396.

[39] Groffman PM, Driscoll CT, Fahey TJ et al. Effects of mild winter freezing on soil nitrogen and carbon dynamics in a northern hardwood forest. Biogeochemistry, 2001, 56(2): 191-213. 